\title{
1871: o ano que não terminou ${ }^{1}$
}

\author{
Márcio Ferreira da Silva
}

resumo Em 1871, com a publicação de Sistemas de Consanguinidade e Afinidade da Família Humana, de Lewis Henry Morgan, a antropologia do parentesco definiu pela primeira vez uma órbita própria, livre do campo gravitacional da história, do direito e da filologia. Neste livro, Morgan propóe um objeto, um método e uma técnica de observação dos fenômenos classificados sob a rubrica "parentesco", que o autor define como a expressão formal e o reconhecimento social das relaçóes naturais entre os indivíduos (1871, p.10). Esta definição está no centro de um dos debates mais antigos da antropologia, a relação entre parentesco e genealogia, que atravessa cento e quarenta anos da disciplina e, a julgar por seus desdobramentos mais recentes, promete ainda muitos anos de polêmica.

palavras-chave Parentesco. Método Genealógico. Lewis H. Morgan. William H. R. Rivers. História da Antropologia.

Meyer Fortes conta uma história engraçada de seus tempos de estudante de antropologia na London School of Economics. Diz que a primeira vez que ouviu falar de Morgan foi em 1931, nos seminários do Professor Malinowski, que o apresentava como um "falso profeta", a "personificaçáo do Reino do Erro na antropologia que o funcionalismo veio derrotar" e um "exemplo lamentável de gênio enganador". O carismático argonauta de nossa disciplina dizia também a seus jovens estudantes que Rivers era a "besta negra” atrás da qual o espectro de Morgan ressurgia como "inspirador da enganosa ênfase causal das formas de casamento nas instituiçôes do parentesco". Fortes conclui: "Morgan era para mim - e, suspeito, para todos os alunos de Malinowski - um dos principais anti-heróis de nossa disciplina” (Fortes, [1969] 2006, p. 4-5).

É provável que, passados oitenta anos, ecos dessas aulas ainda se propaguem no ar. Recentemente, em uma daquelas disciplinas obrigatórias de antropologia do curso de ciências sociais, eis que um jovem estudante, diante do adjetivo da expressão "três sociedades primitivas", que tinha lido na introduçáo de um texto famoso de Margaret Mead, exclamou com olhar indignado: “Mas, professor, isto não é Morgan?". As pegadas do velhote inimigo tinham sido mais uma vez flagradas na cena do crime. O curioso é que este aluno havia aprendido que o evolucionismo jazia no cemitério de uma disciplina cujo desenvolvimento tinha sido a ele apresentado como uma evoluçáo linear, uma história progressista das ideias do Ocidente sobre os $\mathrm{Ou}$ tros, um grande desfile de escolas, com graus crescentes de complexidade, separadas umas das outras por saltos revolucionários. Nesta escalada, seu passo mais notável teria sido aquele, na virada do século $\mathrm{XX}$, que deixou para trás as trevas de sua origem evolucionista e construiu sobre suas cinzas um novo edifício disciplinar, que só recentemente, com a crise das representaçôes, passaria por uma ampla reforma.

$\mathrm{O}$ que vem a seguir faz parte de outra história, em que a marcha progressista da cronologia dá lugar ao tempo reversível dos mitos, em torno de um certo problema antropológico proposto pelo "falso profeta" em 1871, retomado pela "besta negra" alguns anos depois, que atravessou o século XX e ressurgiu na era da 
informática e dos bebês de proveta, por antropólogos que, se Malinowski tivesse tido a oportunidade de conhecer, certamente também teria a eles reservado outros epítetos pitorescos.

Na década de 1860, três obras notáveis inauguram os estudos de parentesco e, através deles, a antropologia social, definindo uma pauta de longa duração, com tópicos como casamento, família, filiação, descendência, sucessão, residência, atitudes e assim por diante. São elas, $O$ Direito Materno (1861), de Johann Jakob Bachofen, Lei Antiga (1861), de Henry Sumner Maine, e Casamento Primitivo (1865), de John Ferguson McLennan. Mas só em 1871, com a publicação de Sistemas de Consanguinidade e Afinidade da Família Humana, de Lewis Henry Morgan, a antropologia do parentesco definiria pela primeira vez uma órbita própria, livre do campo gravitacional da história, do direito e da filologia ${ }^{2}$.

Neste livro, Morgan propóe um objeto, um método e uma técnica de observação dos fenômenos classificados sob a rubrica parentesc $0^{3}$, que o autor define como a "expressão formal" e o "reconhecimento social" das "relaçôes naturais" entre os indivíduos (1871, p.10). Sua reflexão tem como fulcro a comparação de padrôes semânticos que conferem ao parentesco a tal expressáo formal. Como tema privilegiado, Morgan elege a relação entre os padróes, depreendidos dos vocabulários, e correlatos matrimoniais. Sua pesquisa partiu da constataçáo de que os modos como os parentes designavam uns aos outros em culturas indígenas norte-americanas com as quais tinha contato direto eram suficientemente consistentes para serem legitimamente tomados como sistemas que podiam ser descritos e comparados enquanto tais. Esta premissa levou Morgan à elaboraçáo de um minucioso roteiro para a coleta de dados de parentesco, com pequenas instruçôes de preenchimento, reunindo mais de duas centenas de posiçóes genealógicas. Este questionário, que em princípio circulou em uma pequena rede de missionários, em pouco tempo atingiria as mais longínquas regiôes do mundo, graças aos bons ofícios da Instituição Smithsoniana e do serviço consular norte- americano.

Para além da ambição teórica, a pesquisa de Morgan corresponde a um extraordinário esforço de síntese de materiais de campo produzidos pelo próprio autor entre os iroqueses, as tribos de Michigan, os pueblos do Novo México e os Beaver, que se somaram às informaçóes coletadas por uma grande legiáo de colaboradores sob sua supervisão, reunindo dados sobre nada menos que cento e trinta e nove sistemas de parentesco (Tooker, 1997, p.viii).

A comparação dos materiais provenientes da Índia, recolhidos entre as populações tamil e telugo, com aqueles por ele mesmo coletados entre os Sêneca, Ojibwa e outros povos indígenas norte-americanos revelou semelhanças estruturais tão notáveis que, para Morgan, demonstravam conclusivamente a tese da origem asiática dos povos do Novo Mundo. Enquanto isso, o confronto de todo esse material com os da Europa e Oriente Médio revelava a recorrência de um princípio semântico que acabou por merecer atenção especial. Alguns sistemas de parentesco continham termos primários, que se referiam a um número muito limitado de posiçóes genealógicas, como os vocábulos do português "pai", "mãe", "avô", etc. Outros sistemas pareciam conter exclusivamente vocábulos que denotavam classes de parentes, que remetiam a uma quantidade virtualmente infinita de posiçôes genealógicas. A oposição entre termos primários e classes é o que está na base da célebre distinção de Morgan entre sistemas descritivos e classificatórios (1871, p.143-144). Dos parâmetros enunciados pelo autor, cuja variação instaura os dois tipos de sistemas, destacam-se a oposição entre parentes lineares e colaterais, que está presente nos descritivos e neutralizada 
I 87I: O ANO QUE NÃO TERMINOU | 325

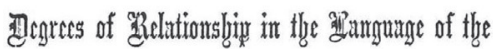

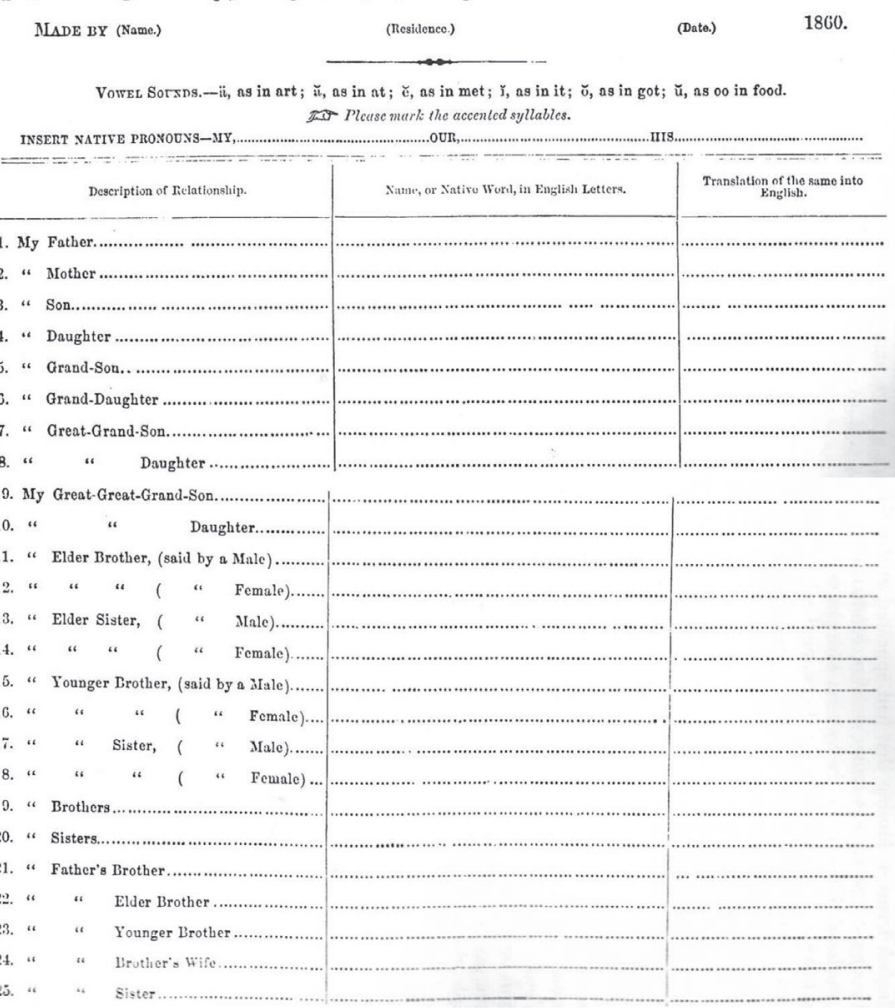

Fig 1: 1a página do Questionário de Morgan (Trautmann, 1987, p.100-101).

nos classificatórios, e a oposição entre parentes paralelos e cruzados que, ao contrário da primeira, está presente nos classificatórios e neutralizada nos descritivos. A distinção entre termos primários e classes serviu também para apontar o caráter analítico dos sistemas descritivos versus o caráter sintético dos sistemas classificatórios.

O livro de Morgan traz por fim uma hipótese sobre a origem do sistema classificatório (Op. cit., p.486) e sobre sua anterioridade histórica em relação aos sistemas descritivos (Op. cit. p.493), além de uma "solução conjetural" do desenvolvimento histórico de seus correlatos sociológicos mais importantes, aqui resumida: intercurso promiscuo > intercasamento ou coabitação de irmãos e irmâs > família comunal $>$ costume havaiano > sistema malaio > organização tribal > sistema tunariano > casamento entre pares > familia bárbara > poligamia $>$ familia patriarcal > poliandria > emergência da propriedade e da sucessáo linear do Estado > família civilizada (Op. cit., p.487-493).

A soluçâa conjetural de Morgan é certamente o ponto mais frágil de seu modelo. Mas é justo assinalar também que ocupa um espaço relativamente discreto na economia de seu livro, em que um terço das seiscentas páginas são tabelas e boa parte das quatrocentas páginas restantes são dedicadas à análise sistêmica dos dados coletados. O famoso exorcismo da história conjetural nos estudos de parentesco promovido por Radcliffe-Brown, por ocasiáo dos setenta anos dos Sistemas de Consanguinidade e Afinidade não deixa pedra sobre pedra ([1941] 1973, p.67-69). Por outro lado, convém notar que a correlação funcional entre vocabulários de parentesco e instituiçóes sociais, outro aspecto fundamental do modelo de Morgan, não parece uma má ideia a Radcliffe-Brown, que a "toma emprestado" naquele mesmo texto sobre o estudo dos sistemas de parentesco, que inicia com um voto de censura a Morgan e seus contemporâneos, mas que logo a seguir propóe que as enigmáticas projeções oblíquas do tipo "mãe = filha do irmáo da mãe = filha do filho do irmão da mãe", etc. dos sistemas crow/omaha sejam interpretadas como inflexóes dos regimes de descendência nos vocabulários (Op. cit., p.73-114).

Contudo, o aspecto mais durável da análise de Morgan não é a meu ver esse que Radcliffe-Brown "toma emprestado", mas outro sobre o qual repousa sua célebre dicotomia. Deixemos claro este ponto: para o autor, os sistemas de paren- 
tesco são descritivos ou classificatórios em relação aos fatos genealógicos a que eles se referem, como não deixa dúvidas sua definição de parentesco, evocada acima. Dizer "o aspecto mais durável da análise de Morgan" não significa, entretanto, afirmar sua entronização como dogma sagrado da disciplina. Ao contrário, a polêmica em torno da relaçáo entre parentesco e genealogia, desde sua primeira erupção em 1871, é um daqueles vulcóes em atividade da antropologia. Contribuindo decisivamente para garantir aos estudos de parentesco um lugar de destaque na disciplina, com sismos de maior ou menor magnitude nos últimos cento e quarenta anos, o debate em torno da relaçáo entre parentesco e genealogia, a julgar por suas erupçóes mais recentes, promete ainda muita lava e fluxos piroclásticos.

O primeiro ataque ao modelo de Morgan veio do outro lado do Atlântico, cinco anos depois da publicação de seu livro. Para John Ferguson McLennan, a análise de Morgan gravitava em torno de dois erros crassos. Para início de conversa, não procurava "a origem do sistema na provável origem da classificação" e, o que era mais grave, conferia aos vocabulários uma importância sociológica que eles não tinham, já que não passavam de fórmulas de boas-maneiras selvagens ou, em suas próprias palavras, "sistemas de saudaçôes mútuas" (McLennan, 1876, p.366). Resumindo, para McLennan, a contribuição de Morgan correspondia a um monumental exercício de erudição em torno de fenômenos irrelevantes.

Em sua réplica a McLennan, publicada no ano seguinte, Morgan reage com a mesma contundência:

Os ataques de McLennan explicam-se pela simples razão de esses quadros, na medida em que exprimem sistemas de afinidade e consanguinidade, contradizerem e refutarem as principais hipóteses e teorias apresentadas em Casamento Primitivo. Seria de esperar, pois, que o autor de Casamento
Primitivo acudisse em defesa das suas ideias preconcebidas. (Morgan, [1877] 1978, p.257).

Rivière (1970, p.xiii), em sua introduçáo editorial a Casamento Primitivo, acredita que o agravamento do estado de saúde de McLennan explica por que o primeiro debate da antropologia ficou sem uma tréplica. Os dois rivais morreram logo depois da troca de farpas, no mesmo ano de 1881, mas a polêmica por eles iniciada, não, embora tenha entrado em um período de hibernação por mais de três décadas, até que Rivers a chamasse de volta ao centro do ringue.

Não conheço nenhuma descoberta, em todo o espectro da ciência, que possa ser mais creditada a um homem que aquela dos sistemas classificatórios por Lewis Morgan. Quero dizer com isso não somente que ele foi o primeiro a apontar claramente a existência deste modo de denotar relacionamentos, mas que foi ele que coletou a vasta massa de materiais pelos quais os caracteres essenciais dos sistemas foram demonstrados e que foi ele o primeiro a reconhecer a grande importância teórica de sua descoberta (Rivers, 1914, p.4-5).

A repercussão da reflexão de Morgan sobre os sistemas classificatórios na Grä-Bretanha, provavelmente graças à resenha de McLennan e ao prestígio de sua teoria do casamento por rapto e da poliandria, foi praticamente nula até sua retomada por Rivers, no início do século XX. Nesse sentido, Langham (1981, p.9) chama a atenção para um dado curioso da história dos estudos de parentesco, flagrado nas três primeiras ediçóes das Notes and Queries, publicadas no fim do período vitoriano. A primeira edição, de 1874, inclui uma tabela de posições genealógicas que, Langham faz questão de assinalar, foi retirada do questionário de Morgan sem reconhecimento de autoria e não vem acompanhada das instruçóes e observaçôes explicativas que a tornassem minimamente 
compreensível aos eventuais interessados. Esta tabela desaparece nas duas edições seguintes, de 1892 e 1899, surgindo em seu lugar um pequeno texto, aparentemente irrelevante, sobre algumas dificuldades inerentes ao estudo dos vocabulários de parentesco de povos exóticos. Mas se a atmosfera na metrópole vitoriana era francamente hostil ao método de Morgan, tudo se passava de outra maneira nas longínquas possessões do império britânico. Um missionário wesleyano, L. Fison, e um explorador naturalista, A. W. Howit, publicam, em 1880, uma coletânea, em coautoria, intitulada $K a$ milaroi e Kurnai, prefaciada por Morgan. Esta coletânea é hoje tomada como o marco inicial dos estudos de parentesco australiano.

A premissa de Morgan de que os sistemas de parentesco correspondiam a vias de acesso direto às instituiçôes sociais foi, no entanto, vigorosamente criticada em sua própria terra por A. Kroeber, na primeira década do século XX, em um texto que, embora náo evoque a memória de McLennan, fez certamente a balança pender para seu lado.

Para o autor, a distinção de Morgan entre sistemas classificatórios e descritivos era equivocada, uma vez que em todos os sistemas de parentesco há termos que classificam. Assim, por exemplo, a palavra "cousin", de um sistema descritivo como o da língua inglesa, compreende trinta e dois tipos de primos apenas de primeiro grau. Projetada aos primos de segundo e terceiro grau, o número de tipos cobertos pela palavra aumenta em progressão geométrica. Kroeber lembra ainda, com razão, que nenhuma língua dispóe de termos diferentes para todas as possibilidades genealógicas e, portanto, nenhum sistema seria propriamente descritivo. Além disso, contra outro aspecto fundamental do modelo de Morgan, a relaçáo entre sistema de parentesco e instituições sociais, o autor chama a atenção de que os vocabulários, enquanto fatos da linguagem que são, "refletem a Psicologia, não a So- ciologia. São determinados, antes de mais nada, pela língua" (Kroeber, [1909] 1969, p.25).

Enfim, parece que o aluno de Boas discorda de Morgan em tudo. Na verdade, porém, discorda de tudo menos do essencial: a interpretação genealógica do parentesco. Os oito famosos princípios ou categorias, que para Kroeber favorecem a comparabilidade dos vocabulários, posteriormente retomados pelas tipologias de R. Lowie (1928) e de G. Murdock (1949), assim como pelas análises formais de W. Goodenough e F. Lounsbury nas décadas de 1950 e 60, não escondem os ecos daqueles parâmetros genealógicos que estão na base da distinção entre sistemas classificatórios e descritivos (Morgan, 1871, p.145-149).

Kroeber náo fica, entretanto, com a última palavra no debate. Quatro anos depois da publicação de seu artigo, W. Rivers, em defesa das teses de Morgan, acerta as contas, em primeiro lugar, com McLennan e seus seguidores, sobre os quais, em uma conferência proferida em 1913, Rivers diz o seguinte:

Aqueles que adotaram [as ideias de McLennan] geralmente se contentam em repetir a conclusão de que o sistema classificatório não é nada mais que um corpo de saudaçốes mútuas e formas de tratamento. Eles não conseguem perceber que, ainda assim, permanece necessário explicar como os termos do sistema classificatório passaram a ser usados em saudaçōes recíprocas, falhando em reconhecer que estão rejeitando o princípio do determinismo na sociologia, ou apenas colocando a uma distância conveniente a consideração do problema de como e por que os termos classificatórios passaram a ser utilizados por tantos povos da Terra [...]. Uma das diversas consequências funestas da crença de McLennan sobre a importância da poliandria na história da sociedade humana foi a incapacidade, por parte de seus seguidores, de perceber a importância do sistema classificatório... (Rivers [1913] 1991, p.75-76). 
Mas Rivers não gasta toda sua munição em McLennan e seus seguidores. Uma bala de prata estava guardada para a hipótese de Kroeber de que os termos de parentesco refletiam a psicologia, não a sociologia. Entrincheirado em sua própria experiência etnográfica adquirida em Fiji, Novas Hébridas e Guadalcanal, em povos cujo sistema de parentesco se caracterizava, por exemplo, por definir um mesmo vocábulo para dizer "tio materno $e$ sogro" ou "tia paterna e sogra”, chega a hora do acerto de contas:

Se não fosse pelo matrimônio entre primos cruzados, o que pode existir para dar ao irmão da mãe uma maior semelhança psicológica com o sogro do que o irmáo do pai, ou à irmá do pai uma maior semelhança psicológica com a sogra do que a irmã da mãe? [...] como é possível que os termos das relaçóes de parentesco não reflitam a sociologia, se tais similaridades psicológicas são elas mesmas o resultado do matrimônio de primos cruzados? (Rivers, [1913] 1991, p.88-89].

Fica assim demonstrado que as preocupaçóes do Professor Malinoswki, manifestadas a seus alunos, não eram infundadas. De fato, o fantasma do "falso profeta", "inspirador da enganosa ênfase causal das formas de casamento nas instituiçóes do parentesco", tinha acabado de migrar para a Grä-Bretanha e se escondia atrás da "besta negra"

A continuidade do projeto de Morgan reclamava, contudo, a invenção de uma nova ferramenta de campo, mais ágil que o pesado roteiro de duzentos e trinta e quatro posiçóes genealógicas, cujo preenchimento requeria razoável habilidade para a abstração e boa dose de paciência tanto do informante quanto do pesquisador. $\mathrm{O}$ método genealógico, desenvolvido por W. H. R. Rivers, com a colaboração de A.C. Haddon, du- rante a célebre expedição ao Estreito de Torres, realizada em 1898, vem responder a essa demanda. A nova ferramenta era capaz de produzir, com precisão e rapidez, as informaçóes chave para os estudos de parentesco. No lugar da coleta de vocábulos de parentesco de línguas exóticas fora de seu contexto de uso, com base em posiçóes de parentesco abstratas, Rivers propóe partir de uma genealogia real, sobre a qual um informante forneceria com exatidão as classificaçóes de seus parentes. Nelas, os indivíduos vivos ou mortos de sua rede seriam identificados por seus nomes próprios em diagramas que garantiriam a coleta eficiente e controlada de um dado vocabulário de parentesco, além de informaçóes sobre preferências matrimoniais, regimes de descendência e de transmissão de bens, migraçôes, direitos, deveres, papéis cerimoniais, padróes onomásticos e assim por diante.

A invençáo do método atendia ao interesse de estabelecer uma base científica para a nova disciplina e à necessidade de assegurar um instrumental adequado para a compreensão daquelas organizaçóes sociais de pequena escala ameaçadas de desaparecimento pela expansão do Ocidente (Langham, 1981, p.66-9) 5 . Rivers observa, no contato com as pequenas populaçôes ágrafas do Estreito de Torres, que as informações genealógicas lá coletadas podiam recuar a muitas geraçôes. Além disso, eram produzidas com notável acuidade, além de serem muito valorizadas pelos nativos. Apresentado à comunidade científica nos anos subsequentes (1900 e $1910^{6}$ ), o método é incorporado às Notes and Queries on Anthropology, a partir de sua $4^{\mathrm{a}}$ edição, de 1912. Em poucos anos, o método de Rivers consagra-se como ferramenta indispensável da pesquisa etnográfica, o "stock-in-trade" do antropólogo (Barnes, 1967, p.104), como o cinzel é do escultor. Nas palavras de R. Laraia, a quem devemos a publicação de sua primeira tradução brasileira, o método é "o instrumento mínimo de trabalho do antropólogo [...], o al- 
fabeto que permite a transcrição da linguagem do parentesco" (Laraia, 1969, p.9).

Mas, propriamente falando, Rivers não inventa o método genealógico. O que faz é transformá-lo em ferramenta analítica da antropologia social e, muito especialmente, dos estudos de parentesco. Versóes arcaicas do método se perdem no tempo. Há séculos, a aristocracia europeia não apenas o cultiva fervorosamente, mas ainda a ele consagra suas formas plásticas mais características, como as que evocam árvores frondosas ou as pegadas de um grou. $\mathrm{O}$ vocábulo inglês "pedigree" é uma corruptela da locução francesa "pied de gru" que é, na origem, rigorosamente sinônima de "genealogia". No entanto, alguns autores, como Barnes (1967, p.103), propóem uma distinção entre os dois vocábulos: genealogia seria o artefato produzido pela análise etnográfica, em formato padrão, a partir de um método rigoroso; pedigree, um conjunto de informaçóes fornecidas pelo nativo nos termos de sua própria cultura. Outros autores, com os quais tendo a concordar, como Barnard e Good (1984, p.21), lembram, entretanto, que tal distinçáo é apenas relativa, uma vez que se, por um lado, pedigree é o modo como um nativo concebe uma genealogia, por outro lado, uma genealogia não é outra coisa senão o modo como um antropólogo concebe um pedigree ${ }^{8}$.

Até 1910, Rivers acreditava na confiabilidade do método genealógico não apenas para o registro das relaçóes sociais, mas também para a produção de dados sobre os vínculos naturais (genéticos) entre os indivíduos nos quais se baseavam as "estatísticas vitais", como a proporção dos sexos em uma população, tamanho médio da família, coeficientes de nascimento e óbito, etc., contribuindo também para o estudo de temas da antropologia biológica, como a hereditariedade, por exemplo. Para o autor, um corpus genealógico trazia informações sobre relações entre indivíduos que eram ao mesmo tempo sociais e naturais, fazendo eco à concepção de parentesco de Morgan. Assim, Rivers, por um lado, não ignora que a relação de filiação é de muitas maneiras definida nas sociedades primitivas e, nesse caso, o que está em jogo é um modelo nativo, que o antropólogo deve observar e descrever. No entanto, na pequena genealogia coletada nas ilhas Salomão, apresentada no texto de 1910 como exemplo do emprego do método, o autor procura "deixar claro" a seu informante, Kurka ou Artur, localizado no lado direito do diagrama, que desejava saber "os nomes de seus pais biológicos e não de alguma outra pessoa que ele assim chamasse, devido ao sistema classificatório de relaçôes" (Rivers, [1910] 1969, p.28).

Rivers infelizmente não nos dá pistas de como consegue "deixar claro" para Kurka o que ele de fato quer saber. Nos contextos culturais em que muitas mulheres são classificadas como mães de um mesmo indivíduo, pode ser relativamente simples esclarecer que aquilo que se quer saber é de que barriga Kurka saiu. Mas como fazer Kurka entender que o que se deseja de fato registrar é o nome de quem efetivamente contribuiu com o espermatozóide que inseminou um dado óvulo de sua mãe, cerca de nove meses antes de seu nascimento? Mesmo que o pesquisador lograsse êxito nesse espinhoso ato de comunicação intercultural, não teria nenhuma garantia de que, novamente para Kurka, os fatos naturais da concepçáo fossem codificados da mesma forma na definição de paternidade. Em suma, biologias nossas e nativas, para Rivers, estavam embaralhadas em um corpus genealógico, pelo menos até 1910 .

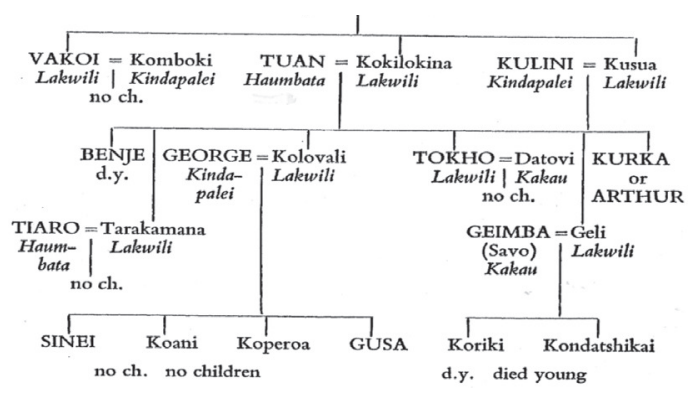

Fig 2: 0 diagrama de Rivers. 
Alguns anos depois, Rivers se livra deste embaralhamento ao se debruçar sobre o material etnográfico coletado em Mota, nas Ilhas Banks. Aí passa a opor nitidamente os conceitos de parentesco e consanguinidade, para o autor entendidos como fenômenos da cultura e natureza, respectivamente. Nas Ilhas Banks, diz o autor,

(...) a relação de pai/mãe não passa a existir pelos fatos da procriação e da parturição (...). São atos como o pagamento da parteira, sua primeira mamada ou o plantio de uma árvore por ocasião de seu nascimento que vão determinar quem serão, para todos os fins sociais, os pais da criança (Rivers, 1915, p.700).

Desta forma, suas ideias passam a coincidir com as de Durkheim, como veremos logo a seguir. Contudo, Rivers continua insistindo em seu ponto principal: a pesquisa genealógica "é o que fornece o método mais exato e conveniente de definir o parentesco" (Op. cit., p.701).

Os estudos de parentesco devem a Durkheim (1898) a definição de corpus genealógico como artefato da cultura e não como dado da natureza. Em um artigo publicado exatamente no mesmo ano em que Rivers e Haddon realizam a expedição ao Estreito de Torres, Durkheim nos alerta que uma genealogia, como objeto da ciência social, de maneira nenhuma se reporta a fenômenos biológicos, mas essencialmente ao universo das representaçóes. Segundo o autor, o laço genealógico, como fato social irredutível, corresponde à presunção da relação de parentesco tal como é estabelecida pelo nativo, e isso é o que tem importância. Como assinala Schneider (1984, p.100), com Durkheim, a biologia ocidental começa a dar lugar às biologias nativas. Mas, de uma forma ou de outra, prossegue Schneider, o fantasma da biologia, qualquer que seja ela, sempre estará lá na tradição dos estudos de parentesco?.
Com um texto provocativo, publicado em 1930, B. Malinowski entra no ringue dos estudos de parentesco. Embora suas ideias de certa forma reverberem o ceticismo de McLennan em relação às propostas de Morgan, nem ele é poupado. Para Malinowski, todos estão errados.

[As] teorias conjeturais do parentesco simplesmente inundaram a literatura antropológica dos tempos de Bachofen, Morgan e McLennan ao revival recente encabeçado por Rivers e sua escola, A. R. Radcliffe-Brown e ultimamente A. Bernard Beacon, T.T. Barnard, Sra. Hoernle, Sra. B. Z. Seligman, para não mencionar a mim mesmo e à trindade californiana do parentesco, Kroeber, Lowie e Gifford - todos influenciados por Rivers. (Malinowski, [1930] 1971, p.95)

Para Malinowski, era preciso oferecer uma alternativa à trilha por onde seguia Rivers e sua corte amestrada em patinar no formalismo e em "memorizar longas listas de termos nativos, seguir persistentemente diagramas e fórmulas complicadas, suar sobre documentos áridos, aturar longos debates dedutivos e o empilhamento de hipóteses sobre hipóteses". Segundo o autor, o "antropólogo médio, embora mistificado e talvez com um pouco de hostilidade, ficou de fora daquele círculo de iniciados" e tinha dúvidas mais que justificadas se "os esforços necessários para dominar a álgebra bastarda do parentesco valiam mesmo a pena" (Op. cit., p.95).

De acordo com Malinowski, o caminho a seguir era outro e deveria partir do problema funcional do parentesco. Neste novo quadro, o mais importante era entender, caso a caso, o que o parentesco realmente significava para os nativos, isto é, o modo como uma dada cultura, organicamente integrada, o define e o pratica no contexto de suas instituiçóes, o que, em certo sentido, retoma a posição de Durkheim.

$[\mathrm{P}]$ or mais primitiva que seja uma comunidade, os fatos da concepção, gestação e parto não são 
relegados à Natureza, mas reinterpretados pela tradição cultural: em todas as comunidades, temos uma teoria sobre a natureza e causas da concepção, um sistema de padróes costumeiros, religiosos, mágicos ou legais, que definem o comportamento da mãe e às vezes também do pai, e temos especificamente um número de tabus observados por ambos durante a gestação (Op. cit., 1930, p.99).

Segundo Malinowski, o parentesco tem como cena inicial o modo como uma cultura interpreta a produçáo de uma criança por um casal e se desenvolve com base em dois processos distintos e complementares: um deles é o de extensáo dos laços instaurados entre pais e filhos, a partir da (e que fundam a) família nuclear. Este processo produziria a parentela, a família extensa e fenômenos a ela relacionados, como os sistemas classificatórios de Morgan. O outro processo envolvido no parentesco, complemento sócio-lógico do primeiro, seria o de sua distorção, com a valorização do cálculo unilinear, agnático ou uterino segundo o caso, gerando os grupos políticos (clãs, linhagens, etc.) (Op. cit., p.102).

Convém chamar a atenção de que sobre tais processos de distorção e extensão cintilam as duas jóias da coroa antropológica britânica da primeira metade do século XX, respectivamente, os conceitos de descent e filiation (Fortes, 1953), que ressurgem triunfalmente na África entre os Nuer, como buth e mar (Evans-Pritchard, 1940), opondo os sistemas politicos aos sistemas de parentesco e casamento e, através deles, as esferas do público e do privado nas sociedades primitivas.

Mas, antes de prosseguir, é preciso deixar claro o que aqui está em jogo: processos de distorção e extensão do quê? De laços genealógicos. Aí parece que estão todos de acordo.

*
Enfim, o método genealógico consagra-se como ferramenta indispensável ao ofício antropológico, como mostram as pesquisas do próprio Rivers e também as de Malinowski entre os trobriandeses, Fortes entre os Tallensi, Evans-Pritchard entre os Nuer, H. Kuper entre os Swazi, Shapera entre os Tswana, Gluckman entre os Lozi e os Zulu, Forde entre os Yakö, Nadel entre os Nuba, Firth entre os Tikopia, Turner entre os Ndembu, Leach entre os Kachin, Kroeber entre os Yurok, Lowie entre os Shoshone e os Crow, Margaret Mead em Manus, Radcliffe-Brown entre os andamaneses, etc.. Uma lista exaustiva dos usuários do método genealógico é um Who is Who da Antropologia Social da primeira metade do século XX.

Nas duas pesquisas que inauguram o período moderno da etnologia sul-americana, nos anos 1960, consagrando um padrão para as geraçóes seguintes, o método de Rivers é vigorosamente retomado por D. Maybury-Lewis (1967) entre os Xavante e por P. Rivière (1969) entre os Trio. Suas coleçóes de genealogias sobre as quais se baseiam suas generalizaçóes estão lá em apêndice a suas monografias pioneiras. Nas décadas seguintes, o método é retomado com o mesmo rigor por J. C. Melatti (1970) entre os Krahó, A. Seeger (1981) entre os Suyá, Viveiros de Castro entre os Araweté (1985) e tantos outros. A lista é longa ${ }^{10}$.

Não obstante, a partir da década de 1960, o debate sobre parentesco e genealogia, como um vulcáo que se julgava extinto, entra em um novo período de atividade que, a rigor, até hoje não cessou, com debates que ficaram conhecidos como o da natureza do parentesco (E. Gellner, 1963; J.H.M. Beattie, 1964), da relação entre genealogia e categoria (D. Maybury-Lewis, 1965; H. Scheffler e F. Lounsbury, 1971), do nascimento virgem (E. Leach, 1966; M. Spiro, 1972) e assim por diante. É nesse período de novos abalos sísmicos que, nos anos oitenta, D. Schneider (1984) provoca um terremoto de grande magnitude na tradição riveriana.

cadernos de campo, São Paulo, n. 19, p. 323-336, 2010 
Em um dos livros de maior impacto nos estudos de parentesco das últimas décadas do século $\mathrm{XX}$, o autor chama a atenção de que a tradição antropológica está ancorada no que denomina "Doutrina da Unidade Genealógica da Humanidade" (1984, p.188). Tal etnoepistemologia europeia - a expressão também é do autor - é o que teria garantido, desde os primórdios da disciplina, a comparabilidade das análises e a própria ideia de parentesco como um universal substantivo das culturas. Mas, atenção! Schneider certamente não supóe que todos os seus colegas estão equivocados porque olham para as culturas exóticas através de lentes europeias. Isso, ele (sabe que) também faz. Sem modelos, europeus ou de outras procedências, a mirada etnográfica não encontra um rumo a seguir. Para o autor, o problema não estaria, portanto, no continente em que tais lentes foram fabricadas, mas no fato de induzirem uma interpretação errônea e etnocêntrica do dado, justamente porque se baseiam na crença de que o parentesco existe em toda parte como um sistema e que, em toda parte, representa, reflete, simboliza, organiza, etc. relaçóes fundadas na reprodução sexuada e em processos a ela concomitantes. Tais pressupostos, para Schneider, não são outra coisa que o surrado senso comum do Ocidente (Op. cit, p.4).

Não há dúvida de que a crítica de Schneider foi fundamental. Contudo, devemos perguntar ao autor, que outro caminho seguir? Ou, para insistir na metáfora óptica por ele proposta, quais seriam então as boas lentes para o estudo do parentesco? Passemos à sua profissão de fé (Op. cit., p.196). Para Schneider, a antropologia é o estudo das culturas particulares. Sua primeira tarefa, pré-requisito de todas as outras, é entender e formular os símbolos, as configuraçôes e os sentidos nos quais uma cultura particular consiste. Até aí, não há desacordo. Mas como lembra F. Héritier, "dito desta forma, o pensamento culturalista ou relativista não é jamais falso" (1996, p.35). Quanto às outras tarefas da disciplina antropológica, o livro de Schneider não dá pistas ao leitor.

Além disso, curiosamente, seu livro se cala diante da outra Doutrina do parentesco, que veio à luz em 1949. Tudo se passa como se, para o autor, o modelo estruturalista também se baseasse naquela mesma Doutrina da Unidade Genealógica da Humanidade. Nesse sentido, o autor flagra na obra lévi-straussiana duas derrapagens comprometedoras. Em uma delas, Lévi-Strauss afirma que "a mitologia é um produto puro e desembaraçado da mente humana, de tal maneira que o parentesco não o é" (apud Schneider, 1984, p.141). Em outra, diz que o "valor da troca não é simplesmente aquele dos bens trocados, uma vez que ele provê os meios de ligar os homens uns aos outros e de sobrepor aos laços naturais do parentesco os laços artificiais da aliança" (Op. cit., 1984, p.173). Não obstante, Schneider lembra que Lévi-Strauss, em outro momento da obra, diz também que um sistema de parentesco não consiste naqueles "laços objetivos de filiação ou consanguinidade dados entre os indivíduos", mas "existe apenas na consciência humana e constitui um sistema arbitrário de representaçôes, não o desenvolvimento espontâneo de uma situação factual". Schneider então conclui: "Eu posso então estar errado em atribuir esta posição a Lévi-Strauss. Ou pode ser que Lévi-Strauss não seja inteiramente consistente" (Op. cit., 1984, p.141).

Se Lévi-Strauss tivesse escrito só essas frases sobre parentesco, seria possível concordar com tal opinião de Schneider. Mas a tradiçáo inaugurada por Lévi-Strauss corresponde a uma verdadeira mudança de paradigma. É o imperativo da troca - e não o império da biologia - o que segundo o autor funda as estruturas do parentesco (Lévi-Strauss, [1949] 1967). Nesse novo quadro, a função de um sistema de parentesco não é tanto representar, refletir, simbolizar, organizar, etc. relaçôes fundadas na reprodução 
sexuada, mas definir impossibilidades e possibilidades matrimoniais (Lévi-Strauss [1965] 1969, p.127). Para além da pretensão de universalidade que ambas manifestam, não há outras semelhanças importantes entre as duas Doutrinas. A hipótese com a qual operamos aqui pode ser assim resumida: o modelo lévi-straussiano autoriza uma reinterpretação das genealogias como registros de uma história infletida, entre outras coisas, por tais possibilidades e impossibilidades, e não mais (ou não somente) como registros de uma história das relaçóes naturais entre os indivíduos ou de representações nativas sobre os fatos da reprodução sustentadas pelo melanésio de tal ou tal ilha. $\mathrm{O}$ que não quer dizer que tais representaçôes não sejam fundamentais para o estudo do parentesco em tal ou tal ilha, já que estão diretamente implicadas no tal "conjunto complexo de crenças, de costumes, de estipulaçooes e de instituições que se designa sumariamente sob o nome de proibição do incesto" (Lévi-Strauss, [1949] 1967, p.10).

Convém lembrar também que, na mesma época em que Schneider formula sua crítica, pesquisas pioneiras como as de F. Héritier (1974; 1981) sobre o funcionamento real das redes matrimoniais dos Samo de Burquina Faso e de M. Segalen (1985; 1991) sobre a aliança de casamento no País Bigouden, Bretanha, abrem caminho para as notáveis contribuições recentes de D. White, M. Houseman e outros, descortinando uma área experimental de estudos de parentesco e computaçáo que assegura muitos anos de vida ao velho método genealógico. Nos últimos cinquenta anos, o diálogo com a informática e com a teoria dos grafos, ramo da matemática que estuda as relaçôes entre as coisas, conferiu ao método de Rivers avanços sem precedentes. Tal aproximação se inicia exatamente na mesma época em que o tema das genealogias entrava na tal zona de turbulência a que me referi acima, com a publicação, em 1960, de um pioneiro artigo do matemático norueguês $\varnothing$. Ore (1960), intitulado com humor "Sexo nos Grafos".

De qualquer maneira, é preciso reconhecer que a crítica de Schneider teve o mérito de contribuir decisivamente para que os estudos de parentesco desembarcassem na contemporaneidade, período marcado pelo fim das grandes narrativas $\mathrm{e}$, consequentemente, pela suspeição em relação às doutrinas de pretensáo universal como a da unidade genealógica da humanidade (apesar do Projeto Genoma) e a do imperativo da troca. Hoje, para um círculo expressivo de antropólogos ultraschneiderianos, o método centenário de Rivers morreu e já vai tarde, depois de tanto desserviço prestado à disciplina pela modelagem genealógica do parentesco. Enquanto isso, para outro círculo, do qual, se estivesse vivo, talvez o próprio Schneider etnógrafo dos Yap, fizesse parte ${ }^{11}$, a modelagem poderia ser eventualmente útil para fornecer ao etnógrafo pistas sobre as redes de relacionalidade a serem retomadas pela análise. Uma coletânea que acaba de vir à luz, organizada por S. Bamford e J. Leach (2009), com um título impossível de traduzir em português mantendo a elegância do original, Kinship and Beyond, traz textos muito interessantes, que representam diversos matizes do espectro de posições aqui resumidas. Esta coletânea expressa seu espírito no subtítulo: "O método genealógico reconsiderado".

$\mathrm{Na}$ direçáo oposta, entretanto, acaba de ser publicado um número especial dos Annales de demographie historique, organizado por Cyril Grange e Michael Houseman (2008). Aqui não se trata de reconsiderar o método genealógico, mas de refundá-lo no século XXI, como revela o próprio título do volume: "As redes de parentesco, refundar a análise". Com textos tão instigantes quanto os da coletânea de Bamford e Leach, seus autores apresentam pesquisas baseadas em rigoroso tratamento informático de dados genealógicos, além de oferecer uma ferramenta computacional elegante (www.kintip.net). Seus autores atualmente integram um 
projeto de "Simulaçóes de Parentesco" (o SimPa, 2009-2012), sediado em Paris, que reúne antropólogos, cientistas da computação, demógrafos, estatísticos, matemáticos, engenheiros e historiadores, todos a anos-luz de 1871. Mas a premissa deste megaprojeto é, com todas as letras, a seguinte: as redes de parentesco evoluem como sistemas dinâmicos.

\section{Complemento idiossincrático}

Em uma passagem de sua Crítica..., ao censurar a homologia entre os vocabulários das cores e os de parentesco, D. Schneider pondera com ironia que "se as cores consistem em ondas percebidas pelo olho, mensuráveis por espectroscópios, as genealogias não consistem em algo do mesmo tipo e náo existem genealogoscópios" (1984, p.125). Schneider está certo. Genealogoscópios, que trazem à mente aquelas engenhocas inventadas pelo Professor Pardal, de fato não existiam nos anos oitenta e hoje continuam não existindo. Mas, talvez, com o passar dos anos, graças a projetos como o Sim$\mathrm{Pa}$, os genealogoscópios migrem dos horizontes das histórias em quadrinhos para o do futuro dos estudos de parentesco.

\section{1: The Year That Never Ended}

abstract In 1871, with the publication of Lewis Henry Morgan's Systems of Consanguinity and Affinity of the Human Family, the anthropology of kinship broke free from the gravitational pull of History, Law and Philology to become established as a field in its own right. Along with a field of study Morgan proposed a method and techniques of data collection of phenomena grouped under the rubric of kinship ("system of consanguinity"). He defined "kinship" as a formal expression and social recognition of natural relations between individuals of a given collectivity (1871, p.10). This definition has been at the center of one of the most longstanding anthropological debates. The relationship between kinship and genealogy has generated controversy for some 140 years and, to judge by the most recent developments, promises to continue to incite debate far into the future.

keywords Kinship and Marriage. Genealogical Method. Lewis H. Morgan. William H. R. Rivers. History of Anthropology.

\section{Notas}

1. Sou grato aos comentários de Fernanda Peixoto, Beatriz Perrone-Moisés e Edson Tosta Matarézio Filho à primeira versão deste artigo e ao apoio da FAPESP (Proc. 2008/53352-3).

2. A biografia de Resek (1960) e o guia de Trautmann (1987) são leituras fundamentais para a compreensão do projeto e da arquitetura de Sistemas de Consanguinidade e Afinidade da Família Humana.

3. Consanguinity, no original.

4. Não me parece convincente a argumentaçáo de Langham (1981, p.90), reiterada por Cardoso de Oliveira (1991, p.19), de que "as descobertas de Rivers guardam expressiva independência em relação às de Morgan”. Esta opinião se baseia, entre outras coisas, no fato de não haver evidências que comprovem que Rivers, ao embarcar para a expediçáo ao Estreito de Torres, tenha tido contato com as ideias daquele autor. No entanto, não fosse a influência das idéias de Morgan, que mais poderia explicar seu interesse pelos vocabulários de parentesco, em um cenário marcado pela crítica de McLennan? Convém lembrar ainda que Rivers faz questáo de assinalar que "o primeiro e mais óbvio" (1969 ([1910], p.30) uso do método genealógico é precisamente para o estudo dos vocabulários de parentesco. Como procuro argumentar, o método de Rivers retoma um legado deixado por Morgan, o que não retira um milímetro de sua importância.

5. Os interessados no desenvolvimento desta "invenção" encontrarão muitas informações interessantes em Langham (1981, p.50-93).

6. A versão de 1910 é a que ficou célebre. No Brasil, há duas traduçốes do texto em questão. A primeira foi publicada em 1969, em uma coletânea de textos de parentesco, organizada por Roque Laraia. A segunda 
veio à luz em 1991, na coletânea de textos de Rivers organizada por Roberto Cardoso de Oliveira.

7. Mas não se pense que tal cultivo fervoroso é coisa do passado, como, por exemplo, revela o cuidadoso estudo de A. Lima (2003) sobre a elite econômica portuguesa no limiar do século XXI, com suas grandes famílias e grandes empreendimentos.

8. Em português - felizmente, eu diria - o termo pedigree, curiosamente dicionarizado sem qualquer adaptação ortográfica (Cf. Aurélio), se consagrou exclusivamente na esfera dos animais de criação.

9. Observe-se que a oposição biologia ocidental versus biologias nativas é rigorosamente homóloga àquela entre genealogia e pedigree proposta por Barnes (1967).

10. Nos anos oitenta, quando era aluno do Museu Nacional, o emprego do método riveriano na pesquisa de campo fazia parte do que os professores denominavam "dever de casa” da pesquisa antropológica. Não é por outra razão que o reencontramos nas dissertaçóes e teses de etnologia indígena daquele período: V. Lea (1986) entre os Kayapó, Teixeira-Pinto (1989) entre os Arara, C. Fausto (1991) entre os Parakanã, A. Vilaça (1992) entre os Pakaa Nova, M. Silva (1993) entre os Waimiri-Atroari, etc.

11. Esta parece ser a opinião de Bamford e Leach (2009, p.13).

\section{Referências bibliográficas}

BACHOFEN, J. J. Das Mutterreich. (versão norte americana: Myth, religion and mother right, selectes writings of J.J. Bachofen. Marx, R. (ed.) [1954] 1967). Princeton: Princeton University Press, 1861.

BAMFORD, S. \& LEACH, J. (Eds.). Kinship and Beyond: The Genealogical Model Reconsidered. Oxford: Berghahn Books, 2009.

BARNARD, A.; GOOD, A. Research Practices in the Study of Kinship. ASA Research Methods in Social Anthropology, No. 2. London: Academic Press, 1984.

BARNES, J. A. Agnation Among the Enga: A Review Article. Oceania, 38, p.33-43, 1967.

BEATTIE, J.H.M. Kinship and Social Anthropology. Man, 64, p.101-3, 1964.

CARDOSO DE OLIVEIRA, R. (Org.). A Antropologia de Rivers. Campinas: Edunicamp, 1991.

DURKHEIM, E. La Famille... L'Année Sociologique, 1, p.306-319, 1898.

EVANS-PRITCHARD, E. Os Nuer - Uma descrição do modo de subsistência e das instituiçôes políticas de um povo nilota. São Paulo: Editora Perspectiva, [1940] 1978.

FAUSTO, C. Os Parakanã: dravidianato e casamento avuncular na Amazônia. Dissertação (mestrado) Museu Nacional, Rio de Janeiro, 1991.

FORTES, M. The Structure of Unilineal Descent Groups. American Anthropologist, v. 55, n.1, p.17-41, 1953.

Kinship and the Social Order - The Legacy

of Lewis Henry Morgan. New Brunswick: Transaction Publishers, [1969] 2006.

GELLNER, E. Ideal Language and Kinship Structure. Philosophy of Science, 24, p. 235-243, 1957.

GRANGE, C. \& HOUSEMAN, M. (Orgs.). Annales de demographie historique, n. 116, 2008.

HÉRITIER, F. Systèmes omaha de parenté et aliance: Étude en ordinateur du fonctionement matrimonial réel d'une société africaine. In: BALLONOFF, P. (ed.) Genealogical Mathematics. Paris-La Haye: Mouton, 1974.

. L'Exercice de la parenté. Paris: Gallimard/ Le Seuil. Coll. Hautes Études, 1981.

- Masculin, Feminin. La pensée de la différence. Paris: O. Jacob, 1996.

LANGHAM, I. The Building of British Social Anthropology: W.H.R. Rivers and his Cambridge Disciples in the Development of Kinship Studies, 1898-1931. Londres: D. Reidel Publishing Company, 1981.

LARAIA, R. de B. (Org.). Organização Social. Rio de Janeiro: Zahar Editores, 1969.

LEA, V. R. Nomes e nekrets kayapó: uma concepção de riqueza. Tese (doutorado) - Museu Nacional, Rio de Janeiro, 1986.

LEACH, E. Virgin Birth. Proceedings of the Royal Anthropological Institute, p.39-49, 1966.

LÉVI-STRAUSS, C. Les structures élémentaires de la parenté. Paris: Mouton, [1949] 1967.

. The future of Kinship Studies. The Huxley Memorial Lecture, 1965. Proceedings of the Royal Anthropological Institute of Great Britain and Ireland for 1965, p.13-22, 1966. Tradução brasileira em LARAIA, R. de B. (Org.). Organização Social. Rio de Janeiro: Zahar Editores, 1969.

LIMA, M. A. P. Grandes Famílias, Grandes Empresas. Série: Portugal de Perto. Lisboa: Publicaçóes Dom Quixote, 2003.

LOWIE, R. A note on relationship terminologies. In: American Anthropologist, 30, p.263-268, 1928.

KROEBER, A. Sistemas Classificatórios de Parentesco. In: LARAIA, R. de B. (Org.). Organizaçâo Social. Rio de Janeiro: Zahar Editores, [1909] 1969.

cadernos de campo, São Paulo, n. 19, p. 323-336, 2010 
336 | Márcio Ferreira da Silva

MAINE, H. S. Ancient Law. Londres: J. Murray, 1861. MALINOWSKI, B. Kinship. Man 30, p.9-29, 1930.

MAYBURY-LEWIS, D. Prescriptive Marriage Systems. Southwestern Journal of Anthropology, 21, p.207-230, 1965.

Akwé-Shavante Society. Oxford:

Clarendon Press, 1967.

MCLENNAN, J. F. Primitive Marriage. Chicago: University of Chicago Press, [1865] 1970.

MELATTI, J. C. O Sistema Social Krahó. Tese (doutorado) - Universidade de São Paulo, São Paulo, 1970.

MORGAN, L. H. Systems of Consanguinity and Affinity of the Human Family. Smithsonian Contributions to Knowledge, No. 17, Washington: Smithsonian Institution, 1871.

MURDOCK, G. Social Structure. New York: Macmillan, 1949.

NEEDHAM, R. Remarks on the Analysis of Kinship and Marriage. In: (Ed.). Rethinking Kinship and Marriage. London: Tavistock, 1971.

ORE, $\varnothing$. Sex in Graphs. Proceedings of the American Mathematical society 11, p.533-539, 1960.

RADCLIFFE-BROWN, A. R. O Estudo dos Sistemas de Parentesco. Estrutura e Função na Sociedade Primitiva. Petrópolis: Vozes, [1941], 1973.

RESEK, C. Lewis Henry Morgan, American Scholar. Chicago: The University of Chicago Press, 1960.

RIVERS, W. H. R. A Genealogical Method of Collecting Social and Vital Statistics. Journal of the Royal Anthropological Institute, 3, p.74-84, 1900.

The Genealogical Method of Anthropology Inquiry. Sociological Review 3, p.1-12, 1910. . Survival in Sociology. The Sociological Review, vol. VI, n. 4, p.293-305, 1913. . Kinship and Social Organization. Londres: Constable \& Co. Ltd., 1914 a. The History of Melanesian Society. Cambridge: Cambridge University Press, 1914b.

RIVIÈRE, P. Marriage among the Trio: A Principle of Social Organization. Oxford: Clarendon Press, 1969.
Editor's Introduction. In: MCLENNAN, J. F. Primitive Marriage. Chicago: University of Chicago Press, [1865] 1970.

SCHEFFLER, H. \& LOUNSBURY, F. A Study in Structural Semantics: The Siriono Kinship System. Englewood Cliffs, New Jersey: Prentice-Hall, 1971.

SCHNEIDER, D. A Critique of the Study of kinship. Ann Arbor. The University of Michigan Press, 1984.

SEEGER, A. Nature and Society in Central Brazil: The Suya Indians of Mato Grosso. Cambridge: Harvard Uiversity Press, 1981.

SEGALEN, M. Quinze générations de Bàs-Bretons. Parenté et société dans le pays bigouden sud 1720-1980. Paris: Presses Universitaires de France, 1985.

. Mariage et parentèle dans Le pays bigouden sud: un exemple de renchaînement d'alliance. In : HÉRITIER-AUGER, F. \& COPET-ROUGIER, E. (Eds.) Les Complexités de l'alliance. Vol II. Éditions des Archives Contemporains. p.177-206, 1991.

SEGALEN, M. \& RICHARD, Ph. Marrying Kinsmen in Pays Bigouden Sud, Britanny. Journal of the Family History. Vol. 11 (2), p.109-130, 1986.

SILVA, M. Romance de Primas e Primos: uma etnografia do parentesco waimiri-atroari. Tese (doutorado) - Museu Nacional, Rio de Janeiro, 1993.

SPIRO, M. Virgin Birth. Man, 3, p.242-261, 1972.

TEIXEIRA-PINTO, M. Os Arara: tempo, espaço e relaçōes sociais em um povo karíbe. Dissertaçâo (mestrado) Museu Nacional, Rio de Janeiro, 1989.

TOOKER, E. Introduction. In: MORGAN, L.H. Systems of Consanguinity and Affinity of the Human Family. Smithsonian Constributions to Knowledge, n. 17, Washington: Smithsonian Institution, [1871] 1997.

TRAUTMANN, T. Lewis Henry Morgan and the Invention of Kinship. Berkeley: University of California Press, 1987.

VILAÇA, A. Comendo como gente: formas do canibalismo wari' (Pakaa Nova). Rio de Janeiro: ANPOCS-EDUFRJ, 1992.

VIVEIROS DE CASTRO, E. Araweté: os deuses canibais. Rio de Janeiro: ANPOCS-Jorge Zahar, 1985.

\section{autor Márcio Ferreira da Silva \\ Professor de Antropologia / USP \\ Doutor em Antropologia Social / MN-UFRJ}

Recebida em 14/09/2010

Aceita para publicação em 14/09/2010

cadernos de campo, São Paulo, n. 19, p. 323-336, 2010 